\title{
$\mathrm{M}^{a}$ del Carmen Aparicio Valls, Palabra de Dios en palabra humana. La inspiración bíblica, Madrid, Biblioteca de Autores Cristianos, 2019, 144 pp., $15 €$.
}

https://doi.org/10.46543/ISID.2029.1011

"El gran misterio de las Sagradas Escrituras reside en que son, al mismo tiempo, Palabra de Dios y palabra humana. Para indicar esta realidad profunda, que se oculta en el texto escrito, decimos que la Escritura está inspirada"(p. ix).

Esta obra es un ensayo breve y sintético que pretende introducir en la cuestión de la inspiración bíblica. La obra se compone de cinco partes. La primera aborda la naturaleza de la inspiración. En las siguientes, la autora expone varias cuestiones estrechamente relacionadas con la inspiración bíblica: en la segunda, la cuestión del canon; en la tercera, el concepto de verdad; en la cuarta, el tema de la interpretación. Finalmente, en la quinta, presenta algunas ideas del documento Inspiración y verdad de la Sagrada Escritura. La Palabra que viene de Dios y habla de Dios para salvar al mundo de la Pontificia Comisión Bíblica.

Comienza el capítulo acerca de la naturaleza de la inspiración recogiendo las acepciones genéricas del término (influjo ejercitado por Dios en la voluntad humana), a la vez que apunta ya la particularidad propia dentro de la tradición judeocristiana. En ella, Dios se sirve de los hagiógrafos haciendo de ellos verdaderos autores (cf. DV 11). Así “la Palabra de Dios, sin dejar de ser tal, se convierte en palabra humana" (p. 4). Por tanto, el don de Dios recae sobre el texto y sobre el hagiógrafo, convirtiéndolos en texto inspirado y en autor inspirado. Ambas realidades no se pueden separar.

El estudio del fenómeno de la inspiración es una cuestión aún abierta. Como todo misterio cristiano, sigue siendo profundizado. Su acento ha cambiado a lo largo de la historia. La inspiración no siempre ha tenido un lugar destacado en la teología, ya que durante muchos siglos se ha abordado a raíz del estudio de cuestiones paralelas: canonicidad, verdad e interpretación.

La misma Sagrada Escritura tiene referencias al proceso de inspiración. En el AT un criterio importante para descubrir la Palabra de Dios es la eficacia de la misma. Se pueden ver varios ejemplos, entre ellos el de la lluvia, que tras caer sobre la tierra y fecundarla vuelve al cielo (cf. Is 55,10-11). En el NT las referencias son más explícitas: en 2 Tim 3,14-16, la autora evidencia la relación estrecha que hay entre el carácter inspirado de la Escritura y su eficacia. En 2 Pe 3,15-16, vemos que el carisma de la inspiración, don de Dios recae en el profeta. Es el Espíritu Santo el que mueve a los autores, y ya aparece la cuestión de la interpretación de la Escritura. 
A lo largo de los primeros siglos no hubo grandes problemas en aceptar el carácter inspirado de la Escritura. Conforme avanza la reflexión teológica se recurren a imágenes para entender el proceso de inspiración, como el dictado (remarcaba la fuerza de la Palabra de Dios), el instrumento (señala la cooperación que hay entre Dios y el hagiógrafo), o la imagen del autor (remarca a Dios como autor de toda la Escritura). En la teología medieval, santo Tomás prefiere la imagen de instrumento y diferencia dos momentos: el de revelación (se recibe la comunicación de Dios) y el de juicio o inspiración (sobre el contenido de la revelación). Ambos momentos, aunque se diferencien, tienen una unidad muy profunda, pertenecen al carisma de la profecía. Sin embargo, en la Escuela de Salamanca, Melchor Cano gira la atención hacia el segundo momento del carisma de profecía: la inspiración. Con su teoría de la inspiración verbal, afirma que la finalidad de la inspiración es la preservación de errores, por ello el mismo Espíritu Santo es quien sugiere las palabras concretas (inerrancia).

A partir de este momento se sucederán varios intentos para evitar la imagen del dictado, algunos de ellos que llevaron a posturas heterodoxas (Lessio), y otros marcaron nuevas líneas de pensamiento en la reflexión teológica (Richard Simon, que intenta casar la inspiración con el origen literario de la Biblia).

La llegada del Concilio Vaticano I formula el "principio de inspiración", unido a la imagen de Dios como autor. Será la Divino afflante Spiritu (Pío XII, 1943), la que vuelva a proponer la analogía de la condescendencia divina de san Juan Crisóstomo. Con ella, se pone en conexión la inspiración con la encarnación.

La Dei Verbum del Concilio Vaticano II recoge que Dios es el autor en cuanto inspirador, pero no el autor literario. A los hagiógrafos se les denomina "verdaderos autores", para reflejar mejor la intervención auténticamente humana dentro del proceso de inspiración. El concilio no entra en cómo acontece la inspiración, ni tampoco profundiza en qué consiste la relación de Dios con los hagiógrafos. Estas inquietudes fueron recogidas por los pontificados de Juan Pablo II y Benedicto XVI, especialmente este último con la Verbum Domini (2008), donde destaca la referencia a María y la Iglesia: igual que en el seno de María se encarnó elVerbo, la Escritura nace también en el seno de la Iglesia.

Respecto del canon, la profesora Aparicio sostiene que los libros que la Iglesia ha recibido y acogido como inspirados son los que constituyen el canon. Se da una relación estrecha entre inspiración y canonicidad: la inspiración es criterio de canonicidad y la canonicidad es garantía de inspiración. El término canon se puede entender por regla, norma, medida, etc. El uso que nos afecta es el teológico: conjunto de libros que forman 
la Biblia y que son normativos para la Iglesia. En el NT ya se citan libros del AT de forma permanente. En el siglo I existían varias colecciones de libros del AT que son usadas en los evangelios. Con Trento, se fija definitivamente el canon de los libros inspirados. Pero esta definición no significa que la Iglesia cree el canon, sino que lo fija: Trento declara canónicos aquellos libros que ya eran normativos para la Iglesia.

No es posible recomponer todos los pasos que llevaron a la elaboración del canon, porque no es producto de una simple reflexión teológica sino de una fe vivida y un don acogido por la comunidad. Por ello no existe ninguna lista de criterios definidos, pero se pueden intuir algunos evidentes. El más claro e importante es el de la inspiración, pero junto a este se pueden concretar algunos más: la regla de fe, las fórmulas primitivas de fe servían para regular la ortodoxia e idoneidad de esos primeros escritos; la apostolicidad, especialmente si el contenido y el tiempo de redacción se corresponde con la época apostólica; y el uso litúrgico en las primeras comunidades, solo se leían en público los libros que se consideraban inspirados.

En cuanto a la relación entre inspiración y verdad, la autora señala que en hebreo el significado principal de verdad está unido al de fidelidad; mientras que, en el griego, el acento está puesto en el aspecto lógico, más abstracto. Ya san Agustín habló de que la verdad bíblica está en toda la Escritura (no solo en algunas partes) y que es una verdad fundamentalmente para la salvación. Melchor Cano unirá este concepto a la lógica demostrativa, lo que conducirá a entender la verdad como ausencia de error (inerrancia). Con el racionalismo, surge una primera crisis en la comprensión de este concepto, ante la cual el Concilio Vaticano I defenderá la integridad de la Sagrada Escritura. En los años siguientes la crisis se agudizó con la extensión de los estudios históricos sobre la Sagrada Escritura.

En el siglo XX, florecen los estudios bíblicos y, con la llegada del Concilio Vaticano II, se marca un nuevo camino de comprensión: "Hay que confesar que los libros de la Escritura enseñan firmemente con fidelidad y sin error, la verdad que Dios quiso consignar en las sagradas letras para nuestra salvación" (DV 11). El estudio de la verdad en la Escritura volvió a cobrar importancia a raíz del sínodo del 2008. En la conclusión se pidió una mayor profundización sobre los conceptos de verdad e inspiración.

Respecto del tema de la interpretación, Aparicio indica que debe ser analizado en una perspectiva dinámica. Los mismos evangelios son ya una interpretación, una selección de palabras, actitudes y gestos de Jesús, a la luz del AT. Con el encuentro de Emaús aparece una clave crucial para la interpretación: "Entonces les abrió la inteligencia para que comprendieran la Escritura" (Lc 24,45). Así pues, en el fondo, la interpretación no es un mero ejercicio intelectual sino un don de Dios. 
Los santos padres fueron los primeros grandes comentaristas de la Escritura. Señalaron dos posibles niveles de lectura: uno más literal (superficial y evidente), y otro más espiritual (profundo y escondido). Recomendaron para una mejor comprensión el dominio de las lenguas originales, de la historia y del contexto del texto bíblico. Seguramente una de las mayores aportaciones viene de san Agustín, con su principio de la caridad como clave de interpretación:"El que juzga haber entendido las divinas escrituras o alguna parte de ellas, y con esta inteligencia no edifica este doble amor de Dios y del prójimo, aún no las entendió" (san Agustín, La doctrina cristiana, I, 36,40; en Obras completas, $\mathrm{XV}$, 91-92). En el medievo las principales aportaciones provienen de la práctica de la lectio divina de la teología monástica y, con santo Tomás, apuntando la necesidad de unir la interpretación a la Tradición, ya que el fin es la comprensión de la verdad de la Revelación.

En la Edad Moderna acontece un cambio de acento sobre el dogma, haciendo un uso más instrumental de la Escritura. La crisis modernista no solo afectará a la verdad bíblica, también a la interpretación. Se suceden una serie de respuestas del Magisterio, en las que destacan la Providentísimus Deus de León XIII (1893), la creación de la Pontificia Comisión Bíblica (1902), y la Divino afflante Spiritu (1943) de Pío XII. Esta última apunta que es tarea del intérprete "averiguar cuál fue el carácter y condición de la vida del escritor sagrado, en qué edad floreció, qué fuentes utilizó, tanto escritas como orales, y qué formas de decir empleó" (DH 3829). Pero especialmente esta tarea no es "solo para rebatir lo que opongan los adversarios, sino también para tratar de encontrar una solución que concuerde fielmente con la doctrina de la Iglesia".

La Dei Verbum apunta a un doble sentido del texto bíblico: el literal y el teológico, ya que es humano y divino. Además, la Escritura "debe ser leída e interpretada con el mismo Espíritu con el que fue escrita". Por eso hace falta tener en cuenta "el contenido y la unidad de toda la Sagrada Escritura" y "la Tradición vida de toda la Iglesia" (DV 12).

La profesora Aparicio presenta, finalmente, tres textos sobre la temática: La interpretación de la Biblia en la Iglesia de la PCB (1993), la Verbum Domini, de Benedicto XVI (2008), e Inspiración y verdad de la Escritura (2004), también de la PCB. Sobre el primero, ella recalca que el documento de la Pontificia Comisión Bíblica señala la limitación de un uso exclusivo de cualquier método, recuperando métodos no solo diacrónicos sino también sincrónicos, y descartando lecturas fundamentalistas. Respecto del segundo, Benedicto XVI insiste en la Iglesia como el lugar originario de la interpretación de la Escritura porque en la fe eclesial se realiza la auténtica interpretación. Frente al riesgo de una lectura solo histórica, el Papa propone una hermenéutica de la fe, que ve la exégesis y la teología como dos dimensiones de una única realidad. Finalmente, 
sobre el documento Inspiración y verdad de la Sagrada Escritura. La Palabra que viene de Dios y habla de Dios para salvar al mundo, la autora señala que documento no pretende ser un punto de llegada sino de partida para que el quehacer teológico siga profundizando en el tema de la inspiración.

La gran ventaja de la obra de la Profa. Aparicio Vallas es que en un breve espacio ofrece una visión bastante completa del fenómeno. La autora tiene una gran capacidad sintética al hacer un breve recorrido histórico de los conceptos. Seguramente el capítulo IV sobre la interpretación sea el más completo. Es cierto también que la autora deja algunas cuestiones abiertas en las que podría concretar más por dónde discurre la investigación actual. Lo cierto es que la obra cumple su objetivo: acercarnos a la cuestión de la inspiración desde una perspectiva completa y amplia, que integra sus elementos más importantes.

Luis María Jiménez de Cisneros Ortiz Facultad de Teología San Isidoro de Sevilla Luisjco_96@hotmail.es

\section{Natale Albino, La Santa Sede e la tutela della proprietà intellettuale. Un'agenda nella diplomazia multilaterale per il bene comune, Trani, Independently published, 2019, 545 pp., 18,72€.}

https://doi.org/10.46543/ISID.2029.1012

La presente ricerca vuole esaminare le ragioni e le modalità con cui la Santa Sede si è approcciata e continua ad accostarsi al tema della proprietà intellettuale (IP) internazionale, in modo da definire i tratti della sua agenda in questo ambito della diplomazia multilaterale e tenendo presente la crescente rilevanza che la proprietà intellettuale sta acquisendo nel Diritto Commerciale e nelle relazioni politiche tra gli Stati.

Il volume edita la tesi di dottorato in Diritto Canonico che il sacerdote Natale Albino, attualmente Segretario della Nunziatura Apostolica in Repubblica Centrafricana e in Ciad, ha conseguito presso la Pontificia Università Lateranense. Il lavoro si compone di quattro parti interconnesse corrispondenti ai quattro capitoli: profili normativi e istituzionali della tutela della proprietà intellettuale nel diritto internazionale; Santa Sede e proprietà intellettuale: una ricostruzione storica; attuale agenda della Santa Sede nella diplomazia multilaterale per la proprietà intellettuale e recepimento delle norme internazionali; le negoziazioni per il Trattato di Marrakesh (2013) e l'apporto della Santa Sede.

Nel primo capitolo, l'autore traccia una panoramica generale sul Diritto dell'IP internazionale definendo i principali assetti normativi e istituzionali. Il 